Case Report

\title{
Left-Sided Patent Ductus Arteriosus in a Right-Sided Aortic Arch
}

\author{
Ming-Yen Ng, ${ }^{1,2}$ Paaladinesh Thavendiranathan, ${ }^{1,3}$ Andrew Michael Crean, ${ }^{1,3}$ \\ Qin $\mathrm{Li}^{3}{ }^{3}$ and Djeven Parameshvara Deva ${ }^{4}$ \\ ${ }^{1}$ Department of Medical Imaging, Toronto General Hospital, Toronto, ON, Canada M5G 2C4 \\ ${ }^{2}$ Department of Diagnostic Radiology, The University of Hong Kong, Hong Kong \\ ${ }^{3}$ Division of Cardiology, Toronto General Hospital, Toronto, ON, Canada M5G 2C4 \\ ${ }^{4}$ Department of Medical Imaging, St. Michael's Hospital, Toronto, ON, Canada M5B 1W8
}

Correspondence should be addressed to Ming-Yen Ng; mingyen.crystal@gmail.com

Received 3 June 2014; Accepted 28 October 2014; Published 17 November 2014

Academic Editor: Salah D. Qanadli

Copyright (C) 2014 Ming-Yen Ng et al. This is an open access article distributed under the Creative Commons Attribution License, which permits unrestricted use, distribution, and reproduction in any medium, provided the original work is properly cited.

We present a 31-year-old female with repaired tetralogy of Fallot (TOF) and right-sided aortic arch (RAA) with left-sided patent ductus arteriosus (PDA) originating from the left brachiocephalic artery. This is a rare finding but most common site for a PDA in TOF and a RAA. To the best of our knowledge, this is the first demonstration of this rare finding on MRI in the literature.

\section{Introduction}

We present a 31-year-old female with repaired tetralogy of Fallot (TOF) (transannular patch repair of the right ventricular outflow tract) and right-sided aortic arch with leftsided patent ductus arteriosus (PDA) originating from the left brachiocephalic artery, which is a rare finding, but most common site for a PDA in individuals with TOF and a rightsided aortic arch. To the best of our knowledge there are no other cases in the literature demonstrated on MRI.

\section{Case Report}

The patient underwent cardiac magnetic resonance imaging (MRI) as part of investigations prior to pregnancy but was otherwise asymptomatic. MRI demonstrated a right-sided aortic arch with mirror image branching and a tubular structure connecting the left brachiocephalic artery to the distal pulmonary trunk (see Figure 1). The magnetic resonance angiogram (MRA) demonstrated blood flow through the tubular structure but the pulmonary-systemic stroke volume ratio (Qp: Qs ratio) was 1:1. Therefore, there was no significant shunt and no intervention was required. Previous imaging was done in a different institution more than twenty years previously and was not available for comparison. The differential diagnosis for this appearance was a modified
Blalock-Taussig shunt but this was ruled out based on surgical notes. The PDA position is consistent with Edward's developmental model of the aortic arch.

\section{Discussion}

In Edward's developmental model of the aortic arch the development of the right-sided aortic arch with mirror image branching occurs due to involution of the dorsal segment of the left arch between the left subclavian artery and descending aorta [1-3]. The right ductus arteriosus also undergoes involution and the remaining left ductus arteriosus usually originates from the left brachiocephalic artery or subclavian artery. This configuration may form a vascular ring with associated symptoms of dysphagia (though this was not the case in our patient). While this is the most common anatomical arrangement in tetralogy of Fallot with a right aortic arch, it is still an extremely rare observation in adult clinical practice.

Other documented positions of the PDA in patients with tetralogy of Fallot include origins from an aberrant left subclavian artery in a right aortic arch, from a diverticulum which also gives off the aberrant left subclavian artery, and from the left common carotid artery in the context of aberrant left subclavian artery, and, rarely, there can be a right PDA 


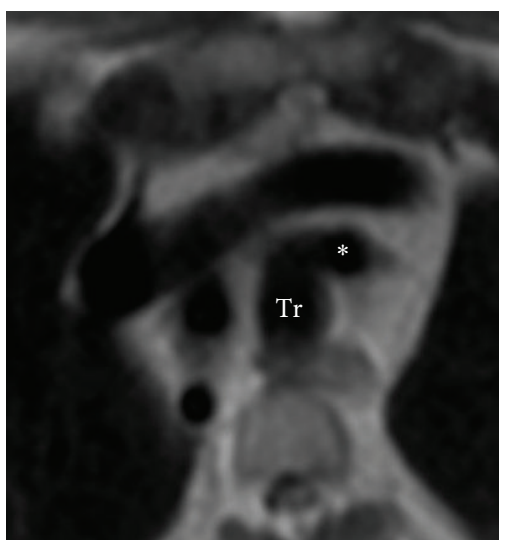

(a)

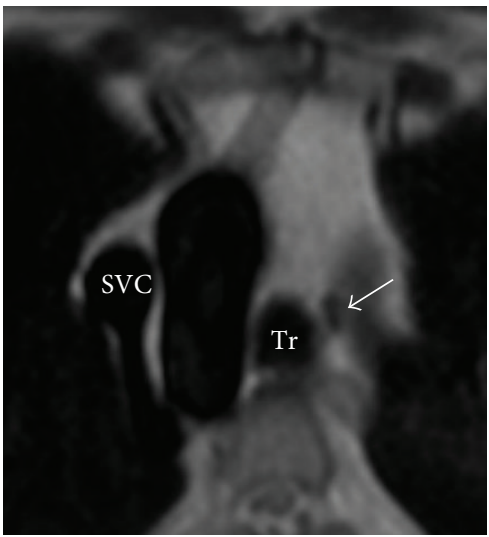

(d)

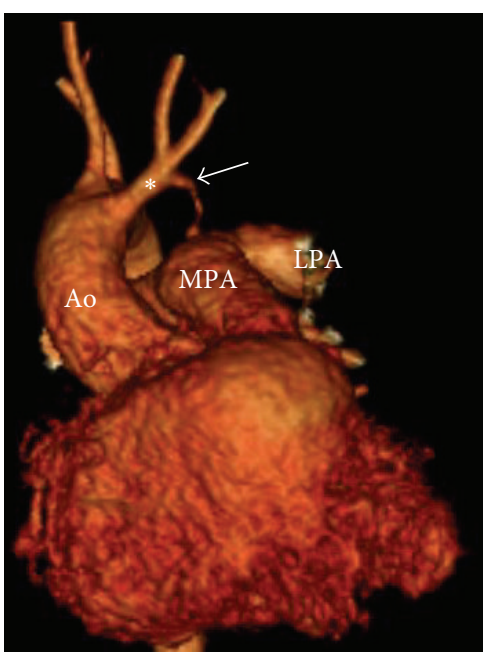

(g)

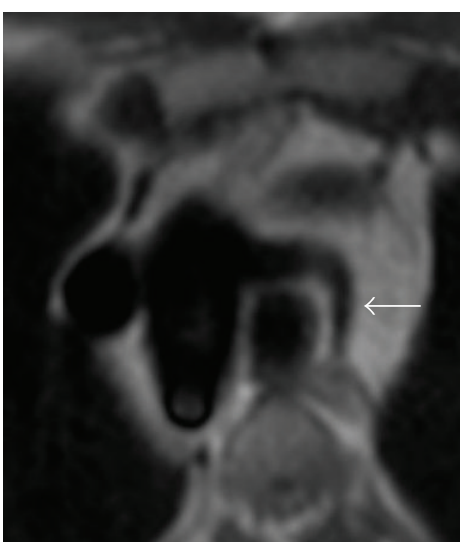

(b)

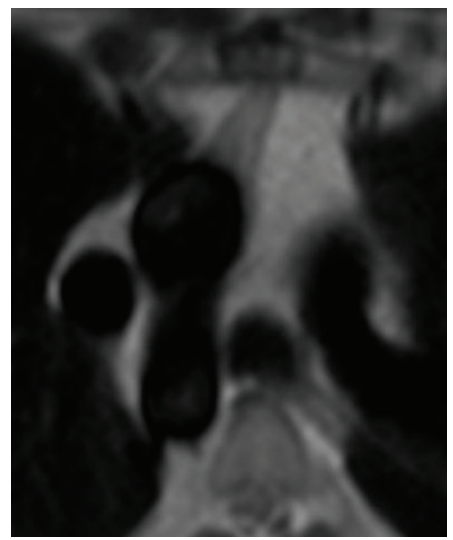

(e)

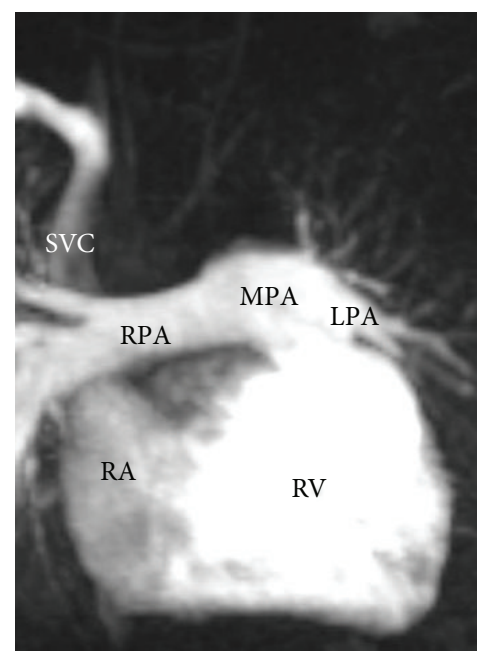

(h)

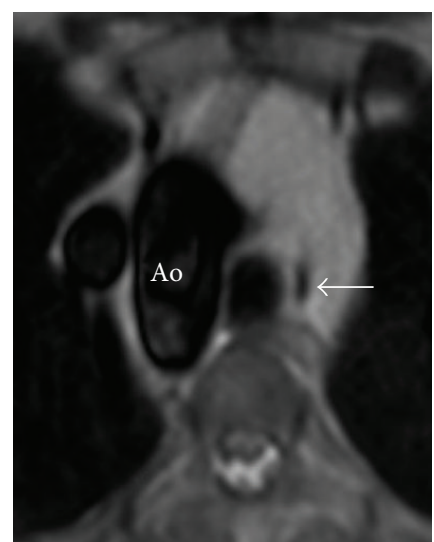

(c)

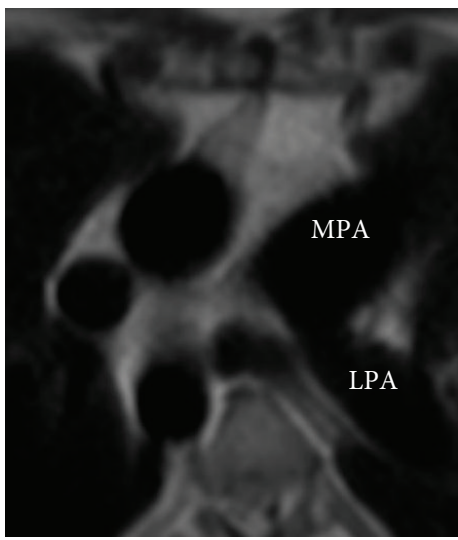

(f)

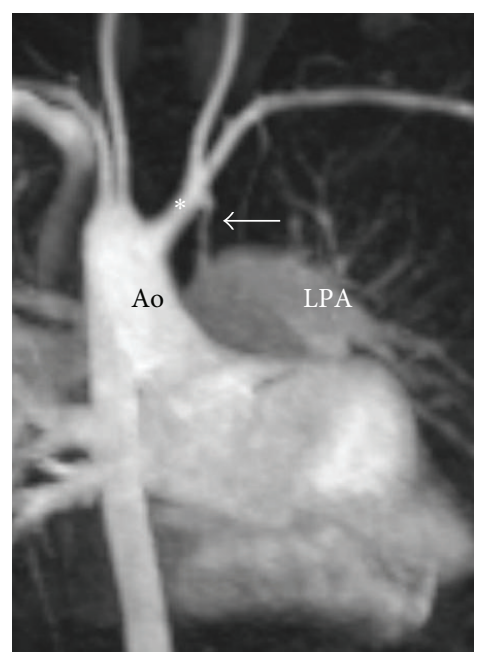

(i)

FIgURE 1: Axial half-Fourier acquisition single shot turbo spin echo images (images (a)-(f)) show the PDA (white arrow) coming off the left brachiocephalic artery and draining into the distal pulmonary trunk. 3D volume-rendered image (image (g), see Supplementary Video 1 in Supplementary Material available online at http://dx.doi.org/10.1155/2014/896071) demonstrating the PDA originating from the left brachiocephalic artery and draining into the distal pulmonary trunk. Maximum intensity projection of the time-resolved MRA (images (h) and (i), Supplementary Video 2), the PDA is not visible during the pulmonary arterial phase (h) but fills once contrast enters the right sided aortic arch during the systemic arterial phase ((i), arrow). Ao: aorta, $*$ : left brachiocephalic artery, LPA: left pulmonary artery, RPA: right pulmonary artery, SVC: superior vena cava, Tr: trachea, MPA: main pulmonary artery, RA: right atrium, and RV: right ventricle. 
connected to the right pulmonary artery. The PDA can arise from the right subclavian artery in a left aortic arch or from a diverticulum when in conjunction with an aberrant right subclavian [4].

\section{Conflict of Interests}

The authors declare that there is no conflict of interests regarding the publication of this paper.

\section{References}

[1] J. Edwards, "Anomalies of the derivatives of the aortic arch system," Medical Clinics of North America, vol. 32, pp. 925-949, 1948.

[2] L. Ramos-Duran, J. W. Nance Jr., U. J. Schoepf, T. Henzler, P. Apfaltrer, and A. M. Hlavacek, "Developmental aortic arch anomalies in infants and children assessed with CT angiography," American Journal of Roentgenology, vol. 198, no. 5, pp. W466-W474, 2012.

[3] A. Türkvatan, F. G. Büyükbayraktar, T. Ölçer, and T. Cumhur, "Congenital anomalies of the aortic arch: evaluation with the use of multidetector computed tomography," Korean Journal of Radiology, vol. 10, no. 2, pp. 176-184, 2009.

[4] J. W. Kirklin and N. T. Kouchoukos, Kirklin/Barratt-Boyes Cardiac Surgery: Morphology, Diagnostic Criteria, Natural History, Techniques, Results, and Indications, Churchill Livingstone, Philadelphia, $\mathrm{Pa}, \mathrm{USA}$, 3rd edition, 2003. 


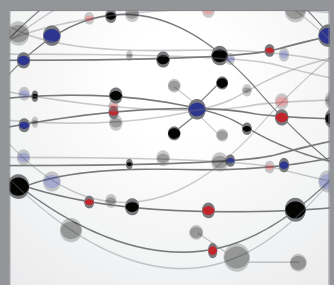

The Scientific World Journal
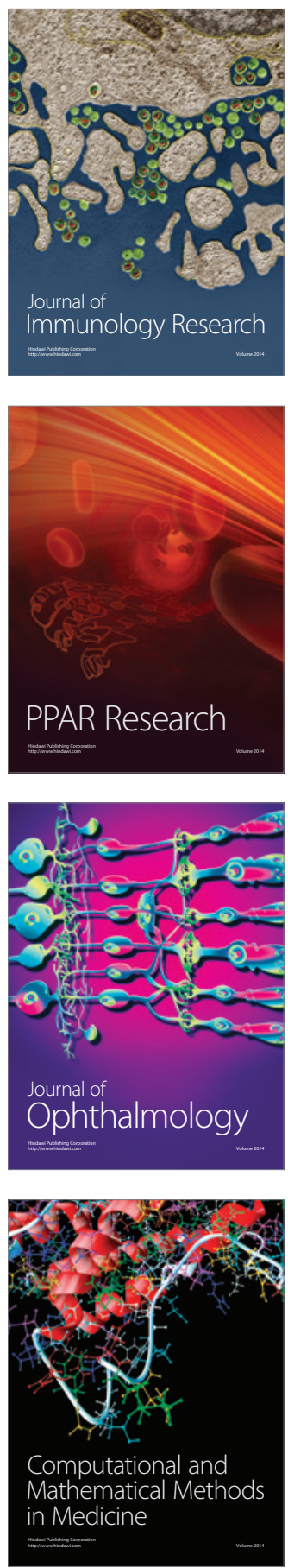

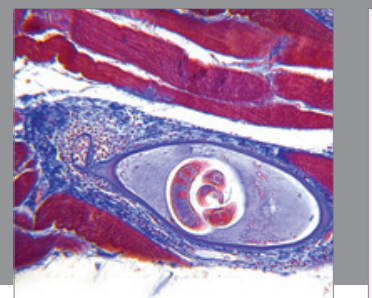

Gastroenterology

Research and Practice
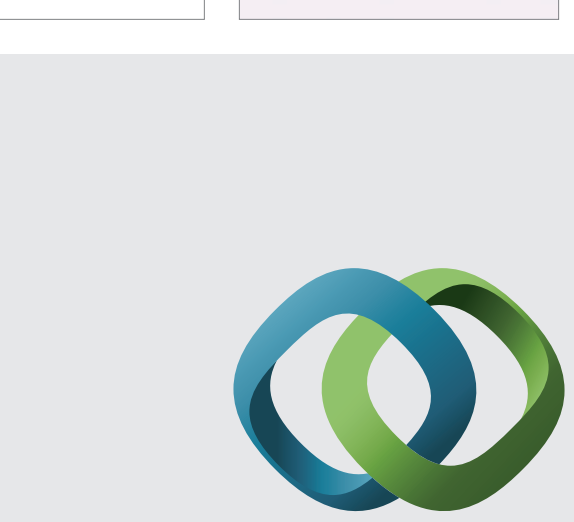

\section{Hindawi}

Submit your manuscripts at

http://www.hindawi.com
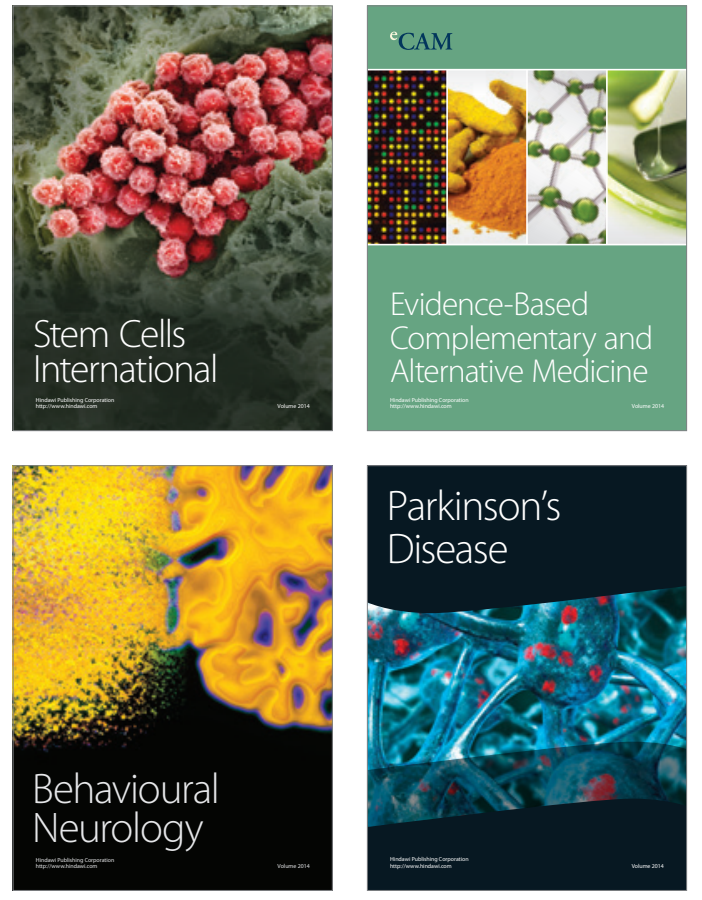
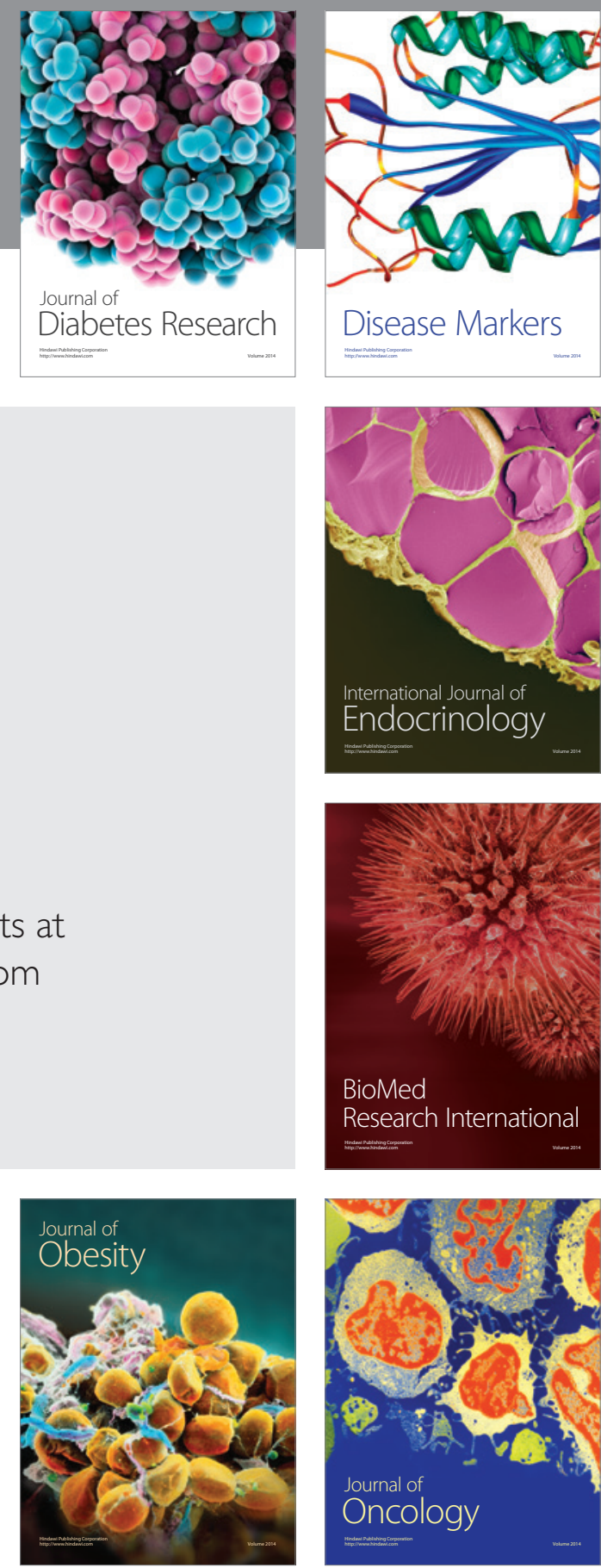

Disease Markers
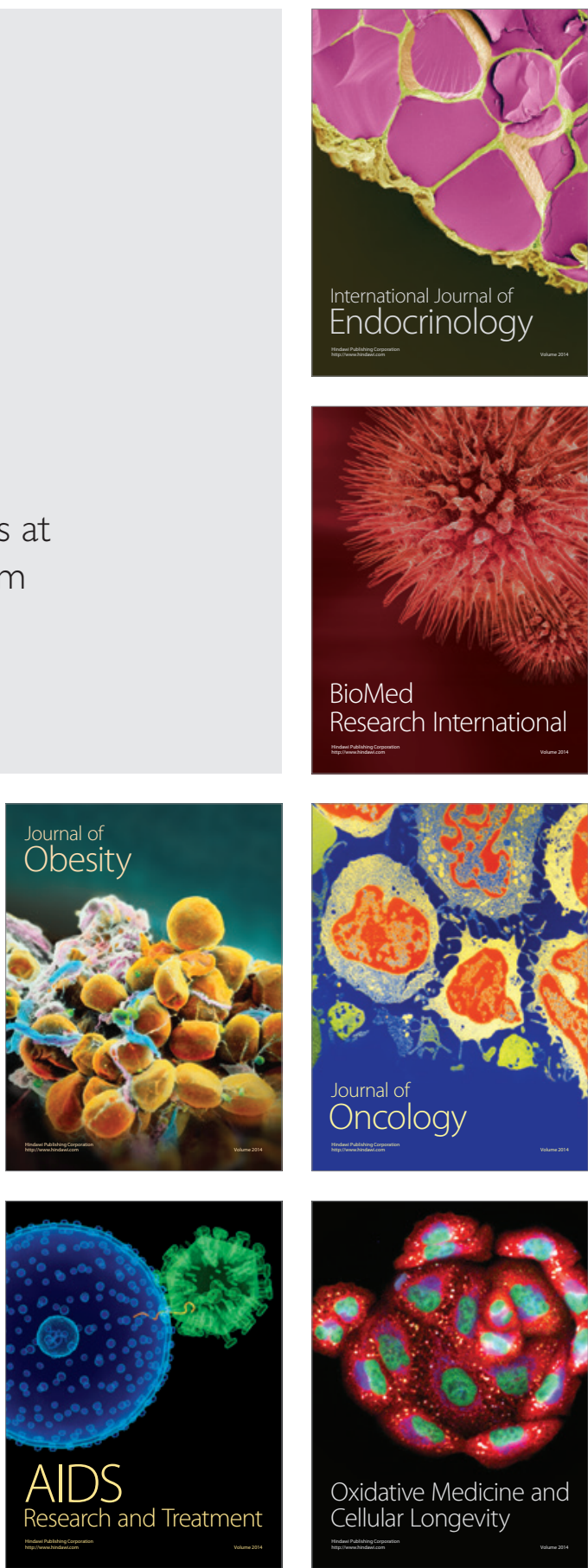